\title{
SELECTIVE EATING OF THE ACYANOGENIC FORM OF TRIFOLIUM REPENS
}

\author{
J. P. A. ANGSEESING \\ St Paul's College, Cheltenham GL5O 4AZ
}

Received 19.i.73

\begin{abstract}
SUMMARY
The cyanogenesis polymorphism is widespread in populations of Trifolium repens L. It is known that cyanogenic plants are selected against by low temperatures and soil water stress. This paper reports on choice chamber experiments which show that the counterbalancing selection against acyanogenic plants is due to selective eating by at least two herbivores (Arion ater L. and Agriolimax reticulatus Muller). The results also show how variations in experimental technique may affect the outcome. $A$. ater became more selective with increased time in the experimental regime and also showed a decrease in selectivity when its food sources were changed while $A$. reticulatus was selective on only two of the three pairs of plants offered. A third species, Arion subfuscus Draparnaud, was found not to be selective.
\end{abstract}

\section{INTRODUGTION}

PARTs of many plants are capable of releasing hydrogen cyanide when damaged, a property found in the leaves of some individuals of white clover, Trifolium repens $\mathrm{L}$. Cyanogenesis in this plant is determined genetically by two unlinked loci. One allele pair $(A c / a c)$ controls the production of cyanogenic glucosides while the other $(L i / l i)$ controls the production of an enzyme capable of hydrolysing these glucosides and releasing HCN (Corkill, 1952).

Most populations of $T$. repens in Europe are polymorphic for both loci (Daday, 1954) and therefore include four phenotypes with respect to HCN production. Plants which are $\mathrm{Ac}-\mathrm{Li}$ - contain both the glucoside and the enzyme and produce HCN immediately upon leaf damage; plants which are Ac-lli li contain the glucosides but no enzyme and therefore release HCN only slowly or not at all, while neither ac ac/Li- nor ac ac/li li individuals can produce HCN.

Low winter temperatures (Daday, 1954, 1965) and soil water stress (Foulds and Grime, 1972) both select against the cyanogenic form of $\mathcal{T}$. repens and various herbivores select against the acyanogenic form of Lotus corniculatus L. (Jones, 1962, 1966), another legume in which the cyanogenesis polymorphism is widespread. If all these factors could be seen to affect both species then the problem as to which major selective forces maintain the polymorphism would be largely solved. The position, however, is more complex than this. Jones (1970) found that winter survival was, at the most, only a trivial selective agent against mature cyanogenic $L$. corniculatus and conflicting results have been obtained concerning selective eating in $T$. repens. Two anecdotal reports suggested that selective eating operated against acyanogenic plants (Corkill, 1952; Daday, 1955) but Bishop and Korn (1969) failed to find selective eating in choice-chamber experiments. More recent work has demonstrated differential eating of the two forms of $T$. repens by several mullusc species, including some used by Bishop and Korn 
(Crawford-Sidebotham, 1972). There is no apparent reason why differential eating experiments, in which animals are offered cyanogenic and acyanogenic plants in sequence, should succeed in demonstrating selection where choice-chamber experiments have failed (Bishop and Korn, 1969). Bishop and Korn's experiments gave rather inaccurate counts of the numbers of leaves eaten, the largest single source of variance in their main experiment being due to the difference in leaf counts made by the two workers (CrawfordSidebotham, 1972). This paper describes choice experiments in which results were obtained more precisely.

\section{Materials AND methods}

The $T$. repens used in the experiments were drawn from a pool of 30 acyanogenic and 20 cyanogenic plants in pots. The plants were originally collected from the same population on the outskirts of Cheltenham. As far as possible pairs of plants (one cyanogenic, one acyanogenic) for choice experiments were matched for leaf size and, secondarily, leaf markings. Also, strongly cyanogenic plants, determined by the picrate paper test, were used in preference to weaker ones.

The herbivores comprised three slug species collected from the same source as the plants. Two species, Arion ater L. and Agriolimax reticulatus Muller, were both actually observed feeding on clover in the wild whereas the third, Arion subfuscus Draparnaud, was not. All the experiments utilised freshly captured adult animals.

Slugs were made to choose between plants as follows. Single individuals of $A$. ater and $A$. subfuscus were kept in plastic lunch boxes wrapped around with black paper. Two square holes, each of about $1.5 \mathrm{~cm}$ wide, were cut in the box lids, one hole at each end. Five leaves of cyanogenic clover, still attached to the parent plant, were pushed through one hole into the box and five leaves of an acyanogenic plant were pushed through the other hole. Great care was taken so that the leaves and petioles were not damaged during this procedure. The holes were then plugged with cotton wool. Twentyfour hours later the test leaves were cut from the plants and scored and fresh leaves were offered to the slugs. Each leaflet was scored individually as $0,0.25,0.5,0.75$ or 1 according to the fraction eaten, giving a total score ranging from 0 to 15 per plant per day. Leaflets which were severed from their petioles without being eaten were also scored as 1 , but their occurrence was recorded separately. A. reticulatus individuals were tested in blackened glass cylinders $10 \mathrm{~cm}$ long and $2.5 \mathrm{~cm}$ in diameter. Each cylinder contained a small pellet of moist cotton wool to maintain humidity. This pellet had water added to it daily. A single leaf was inserted at each end of the cylinder, cyanogenic at one end and acyanogenic at the other. The apertures were then closed with plastic sponge plugs. The leaves were changed daily, each leaflet again being scored separately.

Experiments were carried out either indoors or in a cool greenhouse at a temperature varying from $10^{\circ} \mathrm{C}$. to $16^{\circ} \mathrm{C}$.

\section{Experiments ANd Results}

\section{Experiment 1}

A pair of replicate experiments ( $1 a$ and $1 b)$ were performed with the slug A. ater. Each experiment involved eight animals and four pairs of 
plants and lasted 4 weeks. There was an interval of 3 weeks between the experiments but the second run $(1 b)$ utilised a totally different set of animals and plants. The plants were arranged along the bench in a definite order: $A c$ ac ac $A c A c$ ac ac $A c$; when experiment $1 b$ was set up cyanogenic plants occupied positions on the bench previously allocated to acyanogenic plants and vice versa. Each plant occupied a constant bench position throughout an experiment, but the slugs were moved between the plants in sequence. Two slug chambers were attached to each pair of plants for a week. At the

TABLE 1

Analysis of variance for experiments $1 \mathrm{a}$ and $1 \mathrm{~b}$. This analysis tests the differences in leaflets consumed between individual slugs (Arion Ater), between the various pairs of plants, between cyanogenic and acyanogenic plants and between days. The figures in parentheses in the " $F$ " columns indicate the items which were used as the divisors in obtaining a variance ratio for each mean square

\begin{tabular}{|c|c|c|c|c|c|}
\hline \multirow[b]{2}{*}{ Item } & \multirow[b]{2}{*}{ d.f. } & \multicolumn{2}{|c|}{ M.S. } & \multicolumn{2}{|c|}{$\mathrm{F}$} \\
\hline & & Expt. $1 a$ & Expt. $1 b$ & Expt. $1 a$ & Expt. $1 b$ \\
\hline 1. Slugs (S) & 7 & $40 \cdot 63$ & $11 \cdot 94$ & $2 \cdot 10(10)$ & $<1(10)$ \\
\hline 2. Acyanogenic/ & & & & & \\
\hline cyanogenic $(\mathrm{C})$ & 1 & $745 \cdot 72$ & $825 \cdot 82$ & $13 \cdot 43(7)^{*}$ & $117 \cdot 14(16) * * *$ \\
\hline 3. Days (D) & 6 & $104 \cdot 39$ & $73 \cdot 54$ & $14.93(16) * * *$ & $10.43(16) * * *$ \\
\hline 4. Plant pairs $(\mathrm{P})$ & 3 & $27 \cdot 32$ & $27 \cdot 52$ & $1.41(10)$ & $1.90(10)$ \\
\hline 5. Interaction (CD) & 6 & $52 \cdot 24$ & $60 \cdot 65$ & $7 \cdot 47(16) * * *$ & $8 \cdot 60(16) * * *$ \\
\hline 6. Interaction (CS) & 7 & $13 \cdot 55$ & $27 \cdot 12$ & $1.94(16)$ & $1 \cdot 36(13)$ \\
\hline 7. Interaction (CP) & 3 & $55 \cdot 53$ & $20 \cdot 79$ & $7.94(16) * * *$ & $1.05(13)$ \\
\hline 8. Interaction (DS) & 42 & $4 \cdot 80$ & $4 \cdot 72$ & $<1(16)$ & $<1(16)$ \\
\hline 9. Interaction (DP) & 18 & 8.63 & $9 \cdot 86$ & $1 \cdot 23(16)$ & $1.40(16)$ \\
\hline 10. Interaction (SP) & 21 & $19 \cdot 33$ & $13 \cdot 40$ & $2 \cdot 76(16)^{* * *}$ & $1.90(16) * * *$ \\
\hline 11. Interaction (CDS) & 42 & $6 \cdot 00$ & $5 \cdot 20$ & $<1(15)$ & $<1(15)$ \\
\hline 12. Interaction (CDP) & 18 & $4 \cdot 65$ & 8.45 & $<1(15)$ & $1 \cdot 05(15)$ \\
\hline 13. Interaction (CSP) & 21 & $11 \cdot 94$ & $19 \cdot 87$ & $1.30(15)$ & $2 \cdot 47(15) * *$ \\
\hline 14. Interaction (DSP) & 126 & $4 \cdot 61$ & 6.48 & $<1(15)$ & $<1(15)$ \\
\hline 15. Interaction (CDSP) & 126 & $9 \cdot 22$ & $8 \cdot 05$ & & \\
\hline 16. Estimate of $\sigma^{2} \dagger$ & $333 / 312$ & 6.99 & $7 \cdot 05$ & & \\
\hline
\end{tabular}

$\dagger$ This estimate consisted of the pooled mean squares of items $11-15$ for experiment $1 a$ and of items $11,12,14$ and 15 for experiment $1 b$.

$* 0.05>\mathrm{P}>0.01 ; * * 0.01>\mathrm{P}>0.001 ; * * * \mathrm{P}<0.001$.

end of each week all the slugs were moved on to the next bench position so that by the end of the 4 week experiment all the slugs had had the opportunity to feed off each plant for 7 days.

Table 1 shows a mixed model analysis of variance with two "fixed" effects (the cyanogenic versus acyanogenic choice and the difference between the 7 days following a change in feeding regime) and two " random " effects (between slugs and between pairs of plants). The analysis is very similar to. that used by Crawford-Sidebotham (1972); there are no true replicates and there is therefore no true estimate of $\sigma^{2}$. Consequently, the second-order interactions were tested against the third-order interaction mean square and the pooled mean square from the homogenous second- and third-order interactions was used as an estimate of $\sigma^{2}$. The first-order interactions and main effects were then tested against either this estimate of $\sigma^{2}$ or the appropriate interaction. The two replicates are analysed separately as they were carried out at different times using different individual organisms. The results, however, are very similar for the two.

By far the largest effect in both parts of the experiment, accounting in 
each case for over 20 per cent of the total variance, was the difference between cyanogenic and acyanogenic plants. One other main effect was highly significant and showed that the total quantity of leaves eaten varied greatly between days. Table 2 shows that in each of the 4 weeks of each experiment the quantity of leaves eaten rose throughout the week only to drop sharply at the next change of food plants. The proportion of cyanogenic leaves eaten was greatest at the beginning of the week (table 2).

TABLE 2

Total quantities of leaflets eaten per day for each of the 4 weeks of experiments $1 \mathrm{a}$ and $1 \mathrm{~b}$

\begin{tabular}{|c|c|c|c|c|c|c|c|c|c|}
\hline \multirow[b]{2}{*}{ Expt. } & \multirow[b]{2}{*}{ Week } & \multicolumn{7}{|c|}{ Day } & \multirow{2}{*}{$\begin{array}{l}\text { Week } \\
\text { Total }\end{array}$} \\
\hline & & 1 & 2 & 3 & 4 & 5 & 6 & 7 & \\
\hline $1 a$ & 1 & 4 & $20 \cdot 25$ & 23 & $31 \cdot 5$ & 40 & $37 \cdot 25$ & 59 & 215 \\
\hline $1 a$ & 2 & $30 \cdot 75$ & 28 & $31 \cdot 5$ & $61 \cdot 25$ & $65 \cdot 25$ & 70.75 & $70 \cdot 75$ & $358 \cdot 25$ \\
\hline $1 a$ & 3 & $37 \cdot 25$ & 38 & $36 \cdot 5$ & $55 \cdot 75$ & $54 \cdot 25$ & $57 \cdot 75$ & 82.5 & 362 \\
\hline $1 a$ & 4 & $14 \cdot 25$ & $30 \cdot 25$ & 57.5 & $92 \cdot 5$ & $79 \cdot 25$ & 75 & 100.5 & $449 \cdot 25$ \\
\hline $1 b$ & 1 & 33 & $31 \cdot 25$ & 36 & $63 \cdot 75$ & $38 \cdot 25$ & $58 \cdot 5$ & 52.5 & 313.25 \\
\hline $1 b$ & 2 & 34 & 22 & $50 \cdot 75$ & $58 \cdot 25$ & $65 \cdot 75$ & 67 & 56 & 353.75 \\
\hline $1 b$ & 3 & 21 & 23 & 34 & $57 \cdot 5$ & $79 \cdot 5$ & 63.5 & 51 & $329 \cdot 5$ \\
\hline $1 b$ & 4 & $22 \cdot 5$ & $44 \cdot 5$ & $45 \cdot 5$ & 81.75 & $66 \cdot 75$ & 81.5 & 80.75 & 423.25 \\
\hline Totals & & $196 \cdot 75$ & $237 \cdot 25$ & $314 \cdot 75$ & $402 \cdot 25$ & 489 & $511 \cdot 25$ & 553 & \\
\hline$A c$ totals & & 73.5 & $94 \cdot 75$ & 111 & 124 & 128 & 142 & $125 \cdot 75$ & \\
\hline
\end{tabular}

There are a number of significant interactions but these are not difficult to interpret. The interaction (CD) indicates that the slugs were more selective on some days than others. In fact selectivity increased with familiarity with a particular pair of plants (table 2). The significant interaction (CP) for experiment $l a$ indicates that some plant pairs presented a greater selection differential than others (table 3 ).

TABLE 3

Data showing the proportion of cyanogenic leaflets eaten from the plant pairs in experiment $1 \mathrm{a}$

$\begin{array}{ccc}\text { Plant pair } & \text { Total eaten } & A c \text { percentage } \\ 1 & 340 \cdot 75 & 19 \cdot 0 \\ 2 & 341 \cdot 5 & 18 \cdot 3 \\ 3 & 418 \cdot 5 & 40 \cdot 1 \\ 4 & 283 \cdot 75 & 37 \cdot 4\end{array}$

TABLE 4

Percentage of cyanogenic clover eaten in each of the 4 weeks of experiments $1 \mathrm{a}$ and $1 \mathrm{~b}$

$\begin{array}{cccccc}\text { Expt. } & \text { Week 1 } & \text { Week 2 } & \text { Week 3 } & \text { Week 4 } & \text { Overall } \\ 1 a & 38 \cdot 1 & 29 \cdot 0 & 28 \cdot 8 & 25 \cdot 2 & 29 \cdot 1 \\ 1 b & 39 \cdot 3 & 34 \cdot 0 & 22 \cdot 5 & 20 \cdot 6 & 28 \cdot 6\end{array}$

The significant interaction (SP) is confounded with differences between the 4 weeks of the experiment because different plants were presented to a particular slug in different weeks. There were very large differences in both experiments between the quantities eaten in each week (table 2) and also between the proportion of cyanogenic leaves eaten in each week (table 4). 
Hence there is no indication here that different slugs preferred different plants.

The totals of leaves consumed include 261 cyanogenic and 309 acyanogenic leaflets which were severed from their petioles but not eaten.

\section{Experiment 2}

This experiment was designed to clarify that changes in the food plants diminished the quantity of food consumed. In addition the effect of changing only one plant of the pair at a time was studied. Sixteen individuals of $A$. ater and four pairs of plants were used.

There were four experimental periods. The first lasted 10 days and allowed the slugs to become acclimatised. The usual feeding routine was followed but no counts were made. The ensuing three periods lasted 6 days each and the leaves eaten were scored each day. At the change-over between each of the four periods some of the slugs and some of the plants were moved according to the itinerary in table 5 . The slugs were in three groups:

\section{TABLE 5}

Plan showing the movements of Arion ater individuals and clover plants between the

\begin{tabular}{|c|c|c|c|c|c|}
\hline position & & Period 1 & Period 2 & Period 4 & Period 4 \\
\hline 1 & $\left\{\begin{array}{l}\text { plants } \\
\text { slugs }\end{array}\right.$ & $\begin{array}{c}A c_{1} a c_{1} \\
\text { A B G H }\end{array}$ & $\begin{array}{c}A c_{1} a c_{1} \\
\text { A B C D }\end{array}$ & $\begin{array}{c}A c_{1} a c_{1} \\
\text { A B G H }\end{array}$ & $\begin{array}{r}A c_{1} a c_{1} \\
\text { A B C D }\end{array}$ \\
\hline 2 & $\left\{\begin{array}{l}\text { plants } \\
\text { slugs }\end{array}\right.$ & $\begin{array}{c}A c_{2} a c_{2} \\
\text { E F C D }\end{array}$ & $\begin{array}{c}A c_{2} a c_{2} \\
\text { E F G H }\end{array}$ & $\begin{array}{c}A c_{2} a c_{2} \\
\text { E F C D }\end{array}$ & $\begin{array}{c}A c_{2} a c_{2} \\
\text { E F G H }\end{array}$ \\
\hline 3 & $\begin{array}{l}\text { plants } \\
\text { slugs }\end{array}$ & $\begin{array}{c}A c_{4} a c_{3} \\
\text { I J M N }\end{array}$ & $\begin{array}{l}A c_{3} a c_{3} \\
\mathrm{I} \mathrm{J} K \mathrm{~L}\end{array}$ & $\begin{array}{c}A c_{3} a c_{4} \\
\text { I J M N }\end{array}$ & $\underset{\text { I J } \mathrm{J} K \mathrm{~L}}{A c_{4} a c_{4}}$ \\
\hline 4 & $\begin{array}{l}\text { plants } \\
\text { slugs }\end{array}$ & $\begin{array}{c}A c_{3} a c_{4} \\
\mathrm{O} P \mathrm{~K} L\end{array}$ & $\begin{array}{c}A c_{4} a c_{4} \\
\text { O P M N }\end{array}$ & $\begin{array}{c}A c_{4} a c_{3} \\
\mathrm{O} \mathrm{P} \mathrm{K}\end{array}$ & $\begin{array}{c}A c_{3} a c_{3} \\
\mathrm{O} \mathrm{P} \mathrm{MN}\end{array}$ \\
\hline
\end{tabular}

Group I (slugs A, B, E and F) remained with the same plants throughout the experiment, Group II slugs (C, D, G and H) had both of their plants changed, in a definite pattern, at the end of each period and group III (slugs $\mathrm{I}, \mathrm{J}, \mathrm{K}, \mathrm{L}, \mathrm{M}, \mathrm{N}, \mathrm{O}$ and $\mathrm{P}$ ) had one plant changed at the end of each period. Here again the exchanges were made in a definite pattern; at each changeover half the slugs had their cyanogenic plant exchanged and half had their acyanogenic plant exchanged. Furthermore the alternative exchange was made for each slug at the following change-over so that no group III animal retained a plant for more than two periods.

Each experimental period was divided into two halves of 3 days each when collating the results. Summations were made for each group of slugs over the entire experiment, classifying the scores as occurring within the first half or the second half of a period (table 6). The drop in eating after both plants are changed is confirmed in the comparison between group I and group II slugs. The group II slugs were also less selective overall but showed no difference in their selectivity between the two halves of the test periods. When one food plant only was changed, no reduction in eating or selectivity was noted. There was no significant difference between changes of the cyanogenic source versus changes of the acyanogenic source.

\section{Experiment 3}

Twelve individuals of $A$. subfuscus and three pairs of plants were used in this experiment. The experiment was maintained for 12 days during which 
TABLE 6

(a) Results from experiment 2. Total number of leaflets eaten by each group of slugs in $(a)$ the first 3 days and $(b)$ the second 3 days after the beginning of an experimental period

\begin{tabular}{|c|c|c|c|c|c|c|}
\hline Slugs & \multicolumn{2}{|c|}{ (a) First 3 days } & & \multicolumn{3}{|c|}{ (b) Second 3 days } \\
\hline Group I (4 slugs) & $\left\{\begin{array}{l}A c \text { score } \\
a c \text { score }\end{array}\right.$ & $\begin{array}{c}72 \cdot 5 \\
183 \cdot 75\end{array}$ & $256 \cdot 25$ & $\begin{array}{l}A c \text { score } \\
a c \text { score }\end{array}$ & $\begin{array}{r}74 \cdot 5 \\
194 \cdot 5\end{array}$ & 269 \\
\hline Group II (4 slugs) & $\begin{array}{l}\left\{\begin{array}{l}A c \text { score } \\
a c \text { score }\end{array}\right. \\
A c \text { score* }\end{array}$ & $\begin{array}{l}36 \cdot 75 \\
73 \cdot 75 \\
62 \cdot 25\end{array}$ & $110 \cdot 5$ & $\begin{array}{l}A c \text { score } \\
a c \text { score }\end{array}$ & $\begin{array}{l}117 \cdot 5 \\
196 \cdot 25\end{array}$ & 313.75 \\
\hline Group III (8 slugs) & $\begin{array}{l}a c \text { score* } \\
A c \text { score } \\
a c \text { score } \dagger\end{array}$ & $\begin{array}{l}165 \\
56 \\
192 \cdot 75\end{array}$ & 470 & $\begin{array}{l}A c \text { score } \\
a c \text { score }\end{array}$ & $\begin{array}{l}128.5 \\
349.5\end{array}$ & 478 \\
\hline
\end{tabular}

* Ac plant, only, changed; $†$ ac plant, only, changed.

(b) Contingency $\chi^{2}$ tests on the above data:

\begin{tabular}{|c|c|c|c|}
\hline & 1st 3 days & 2nd 3 days & \\
\hline \multirow[t]{2}{*}{$\begin{array}{l}\text { Group I total } \\
\text { Group II total }\end{array}$} & $\begin{array}{l}256 \cdot 25 \\
110 \cdot 5\end{array}$ & $\left.\begin{array}{l}269 \\
313 \cdot 75\end{array}\right\}$ & $\chi_{1}^{2}=51.3 \quad(P<0.001)$ \\
\hline & $A c$ score & $a c$ score & \\
\hline \multirow[t]{2}{*}{$\begin{array}{l}\text { Group I } \\
\text { Group II }\end{array}$} & $\begin{array}{l}147 \\
154 \cdot 25\end{array}$ & $\left.\begin{array}{l}378 \cdot 25 \\
270\end{array}\right\}$ & $\chi_{1}^{2}=7.3 \quad(P<0.01)$ \\
\hline & $A c$ change & $a c$ change & \\
\hline $\begin{array}{l}A c \text { score } \\
a c \text { score }\end{array}$ & $\begin{array}{r}62 \cdot 25 \\
165 \cdot 00\end{array}$ & $\left.\begin{array}{l}56 \\
192 \cdot 75\end{array}\right\}$ & $x_{1}^{2}=1.5 \quad(P>0.05)$ \\
\hline
\end{tabular}

time most of the slugs ate very little. Shortly after the twelfth day a number of slugs died and the experiment was terminated. There was no difference between the scores of cyanogenic and acyanogenic leaflets eaten (table 7).

TABLE 7

Record of the cyanogenic (Ac) and acyanogenic (ac) scores in choice experiments using Arion subfuscus

\begin{tabular}{|c|c|c|c|c|c|c|c|c|c|c|c|c|c|}
\hline & & & & & & & & & & & & & \\
\hline & 1 & 2 & 3 & 4 & 5 & 6 & 7 & 8 & 9 & 10 & 11 & 12 & Total \\
\hline score & $\begin{array}{l}20 \cdot 25 \\
10 \cdot 5\end{array}$ & $\begin{array}{l}6 \cdot 5 \\
4 \cdot 75\end{array}$ & $\begin{array}{l}8 \\
2 \cdot 75\end{array}$ & $\begin{array}{l}8.5 \\
6\end{array}$ & $\begin{array}{l}5 \cdot 25 \\
5 \cdot 5\end{array}$ & $\begin{array}{l}0.25 \\
7.5\end{array}$ & $\begin{array}{l}10 \\
10\end{array}$ & $\begin{array}{l}1 \cdot 75 \\
5 \cdot 25\end{array}$ & $\begin{array}{l}0.25 \\
4 \cdot 25\end{array}$ & $\begin{array}{l}0.75 \\
5\end{array}$ & $\begin{array}{l}14 \cdot 5 \\
14 \cdot 75\end{array}$ & $\begin{array}{l}14 \\
11 \cdot 75\end{array}$ & $\begin{array}{l}90 \cdot 0 \\
88.0\end{array}$ \\
\hline
\end{tabular}

\section{Experiment 4}

This experiment utilised 18 A. reticulatus individuals and lasted 3 weeks; there were three pairs of test plants, with six slugs attached to each pair of plants at any one time. At the end of each week the slugs were moved to the next pair of plants in sequence so that by the end of the experiment all the slugs had been attached to all the plants.

The analysis of the results is similar to that of experiment 1 , and is presented in table 8 . There is no exact variance-ratio test for the choice main effect as both the interactions (CS) and (CP) are significant, so the approximate method has been used (Snedecor and Cochran, 1971, pp. 368369). Despite only 33 per cent of the leaflets eaten being cyanogenic, the choice main effect is not significant. As all three first-order interactions 
involving choice are significant, this means the interpretation of the results is not straightforward. One of these interactions, choice $\times$ plant pair, is the largest single effect accounting for over 12 per cent of the total variance.

\section{TABLE 8}

Analysis of variance for experiment 4. This analysis tests the differences in leaflets consumed between individual slugs (Agriolimax reticulatus), between the three pairs of test plants, between cyanogenic and acyanogenic plants and between days. The figures in parentheses in the " $F$ " column indicate the items which are used as the divisors in obtaining a variance ratio for each mean square

Item d.f. M.S. F

1. Cyanogenic/acyanogenic (C)

2. Days (D)

3. Slugs (S)

4. Plant pairs $(\mathrm{P})$

5. Interaction (CD)

6. Interaction (CS)

7. Interaction (CP)

8. Interaction (DS)

9. Interaction (DP)

10. Interaction (SP)

11. Interaction (CDS)

12. Interaction (CDP)

13. Interaction (CSP)

14. Interaction (DSP)

15. Interaction (CDSP)

$1 \quad 27 \cdot 65$

0.91

$0 \cdot 75$

3.59

1.53

$0 \cdot 81$

8.45

$\begin{array}{rrr}2 & 0.49 & 1.05(16)\end{array}$

0.55

0.72

$0 \cdot 47$

$3.03(\dagger)$

$2.46(16) *$

17
2

$1.04(10)$

$4.99(10)^{*}$

$4 \cdot 13(16) * * *$

17
2

$2 \cdot 19(16) *$

102

$1.05(16)$

34

102

$0 \cdot 47$

$1.95(16)$

12
34

$0.39 \quad 1.00(15)$

$1 \cdot 20(15)$

$<1(15)$

16. Pooled M.S. for items $11-15$

$204 \quad 0.30$

$204 \quad 0.39$

$<1(15)$

$0 \cdot 37$

* $0.05>\mathrm{P}>0.01 ; * * 0.01>\mathrm{P}>0.001 ; * * * \mathrm{P}<0.001$.

$\dagger \mathrm{F}=\left(\mathrm{MS}_{1}+\mathrm{MS}_{13}\right) /\left(\mathrm{MS}_{6}+\mathrm{MS}_{7}\right)$. The degrees of freedom are: $n_{1}=1.03$ and $\mathrm{n}_{2}=2 \cdot 40$

\section{TABLE 9}

(a) Quantities of cyanogenic ( $A c)$ and acyanogenic (ac) leaflets consumed during each week of the experiment with Agriolimax reticulatus for each of the three pairs of plants used

\begin{tabular}{|c|c|c|c|c|c|}
\hline Plant pair & Week 1 & Week 2 & Week 3 & $\begin{array}{l}\text { Plant } \\
\text { totals }\end{array}$ & $\begin{array}{l}\text { Plant pair } \\
\text { totals }\end{array}$ \\
\hline$\left\{\begin{array}{l}A c \\
a c\end{array}\right.$ & $\begin{array}{l}20 \\
14 \cdot 75\end{array}$ & $\begin{array}{l}17 \\
17.5\end{array}$ & $\begin{array}{l}18 \cdot 75 \\
20\end{array}$ & $\left.\begin{array}{l}55 \cdot 75 \\
52 \cdot 25\end{array}\right\}$ & 108 \\
\hline$A c$ & $\begin{array}{c}9 \cdot 5 \\
42 \cdot 75\end{array}$ & $\begin{array}{l}13.5 \\
43.5\end{array}$ & $\begin{array}{l}17 \cdot 75 \\
38 \cdot 5\end{array}$ & $\begin{array}{r}40 \cdot 75 \\
124 \cdot 75\end{array}$ & $165 \cdot 5$ \\
\hline $3\left\{\begin{array}{l}A c \\
a c\end{array}\right.$ & $\begin{array}{l}17 \cdot 5 \\
29 \cdot 5\end{array}$ & $\begin{array}{l}13 \\
38\end{array}$ & $\begin{array}{l}14 \cdot 25 \\
41 \cdot 75\end{array}$ & $\left.\begin{array}{r}44 \cdot 75 \\
109 \cdot 25\end{array}\right\}$ & 154 \\
\hline Totals & 134 & $142 \cdot 5$ & 151 & $427 \cdot 5(3$ & $A c ; 67 \%$ \\
\hline
\end{tabular}

(b) $\chi_{1}^{2}$ for the difference between the $A c$ and $a c$ totals eaten from plant pair $2=42.7(\mathrm{P}<0.001)$.

$\chi_{1}^{2}$ for the difference between the $A c$ and $a c$ totals eaten from plant pair $3=26.6(P<0.001)$

This is readily understood by reference to table 9 where it may be seen that about equal amounts were eaten from the two members of plant pair one while from pairs two and three the leaflets eaten were predominantly acyanogenic. The acyanogenic versus cyanogenic totals are significantly different for each of these two pairs (table $9 b$ ) and it can be seen that more acyanogenic leaflets were eaten on all 7 days and by 17 out of the 18 animals 
(table 10) if these two pairs only are considered. Consequently it may be concluded that selection of acyanogenic plants was occurring within plant pairs two and three although not within pair one of the experiment as a whole. It happens that the cyanogenic plant used in pair one was only moderately cyanogenic whereas those in pairs two and three were strongly cyanogenic!

TABLE 10

(a) Data extracted from experiment 4 showing the quantities of leaflets eaten from plant pairs 2 and 3 by each individual slug

$\begin{array}{cccccc}\text { Slug } & A c \text { total } & a c \text { total } & \text { Slug } & A c \text { total } & a c \text { total } \\ 1 & 5 & 17 \cdot 5 & 10 & 6 \cdot 75 & 10 \cdot 25 \\ 2 & 9 \cdot 25 & 8 \cdot 5 & 11 & 3 \cdot 5 & 9 \cdot 25 \\ 3 & 7 \cdot 5 & 14 \cdot 75 & 12 & 3 \cdot 75 & 16 \\ 4 & 3 & 13 \cdot 5 & 13 & 5 & 22 \\ 5 & 1 \cdot 5 & 5 & 14 & 2 \cdot 25 & 18 \cdot 25 \\ 6 & 3 \cdot 5 & 17 \cdot 25 & 15 & 4 \cdot 25 & 13 \cdot 5 \\ 7 & 6 \cdot 25 & 17 \cdot 25 & 16 & 7 \cdot 5 & 8 \cdot 5 \\ 8 & 5 \cdot 75 & 8 \cdot 75 & 17 & 1 \cdot 25 & 9 \\ 9 & 5 & 11 \cdot 25 & 18 & 4 \cdot 5 & 13 \cdot 25\end{array}$

(b) Data showing the numbers of cyanogenic and acyanogenic leaflets eaten from plant pairs 2 and 3 on each of the 7 days

\begin{tabular}{|c|c|c|c|c|c|c|c|}
\hline & & & & Day & & & \\
\hline & 1 & 2 & 3 & 4 & 5 & 6 & 7 \\
\hline Ac & $\begin{array}{l}12 \cdot 25 \\
20 \cdot 5\end{array}$ & $\begin{array}{l}15 \cdot 5 \\
40\end{array}$ & $\begin{array}{l}12.5 \\
43.5\end{array}$ & $\begin{array}{l}16 \cdot 25 \\
29 \cdot 25\end{array}$ & $\begin{array}{c}7 \cdot 75 \\
30 \cdot 5\end{array}$ & $\begin{array}{r}9.75 \\
35 \cdot 75\end{array}$ & $\begin{array}{l}11.5 \\
34.5\end{array}$ \\
\hline
\end{tabular}

The other significant effects included that between days, although this showed no definite trend such as appeared in the $A$. ater experiments (table 10), and that between plants. It is noteworthy that it is plant pair one from which significantly less leaflets were eaten than from the other two pairs (table 9).

\section{Drscussion}

These experiments lead to the conclusion that the herbivorous slugs Arion ater and Agriolimax reticulatus select against the acyanogenic form of Trifolium repens whereas Arion subfuscus does not. These results for the two Arion species are in entire agreement with the differential eating experiments of Grawford-Sidebotham (1972) but those obtained with $A$. reticulatus are not in accordance with earlier work. Bishop and Korn (1969) concluded that A. reticulatus and also Helix aspersa Müll., a snail, were not selective on $T$. repens. As Jones $(1962,1966)$ had found $A$. reticulatus to be selective on Lotus corniculatus, they also concluded that selection in one of these plant species could not be extrapolated to the other. Crawford-Sidebotham (1972) concurred with the latter as he found $A$. reticulatus was a differential feeder on $L$. corniculatus but not $T$. repens phenotypes and the converse occurred in another species, Arion hortensis Fer. Whereas his results did not disagree with Bishop and Korn's for $A$. reticulatus, they did for $H$. aspersa.

Part of the reason for the insensitivity of Bishop and Korn's experiments (1969) on selection by $H$. aspers $a$ and $A$. reticulatus as compared with GrawfordSidebotham (1972) and the present paper respectively, may lie in their 
scoring technique. Crawford-Sidebotham (1972) pointed out that the largest single effect in their experiments on $H$. aspersa, accounting for 25 per cent of the total variance, is for the difference between the two observers. Furthermore, the coefficient of correlation between observers is only 0.73 therefore the correlation between leaves scored as eaten and leaves actually eaten must approximate this figure. Although this is clearly significantly different from zero, it is not a good result for an experiment where the leaves eaten were supposed to be scored by direct counting. There are two other possible explanations for the insensitivity of the experiments. The results described above for $A$. ater, show that the animals are relatively unselective when the experimental routine has just been inaugurated and when the food sources have been changed, and indicate that laboratory conditions may affect the behaviour of an animal sufficiently to change its selectivity. It was for this reason that a field survey has been carried out to verify slug selection against acyanogenic $\mathcal{T}$. repens (Angseesing and Angseesing, 1973). Another explanation for Bishop and Korn's (1969) results is that herbivores may eat cyanogenic leaves when no other food is available. Jones (1966) showed that $A$. reticulatus will eat cyanogenic $L$. corniculatus under these conditions and Crawford-Sidebotham (1972) found that the effect due to presence or absence of alternative food was the largest one in most of his experiments. Bishop and Korn (1969) started their experiment on $H$. aspersa with plants possessing 100-200 leaves and scored their plants only at the end of each experimental block. As their mean scores of eaten leaves average 115 leaves per plant per block and as each plant was apparently used in more than one block, there could have been few leaves left on most plants at the end of the experiment. Hence their animals may have eaten cyanogenic clover because there was insufficient acyanogenic food available.

The results showing that $A$. reticulatus will eat cyanogenic plants when no other food is supplied, suggest a possible explanation for why CrawfordSidebotham (1972) did not find differential eating of $T$. repens by this slug. He suggests (Crawford-Sidebotham, pers. comm.) that the cyanogenic individuals in each of the two plant pairs within which selection was found in my experiments were more strongly cyanogenic than in his own experiment. This is supported by the lack of selection in the plant pair which incorporated a cyanogenic plant of only moderate strength and the report by Jones (1966) of a quantitative effect when the vole Microtus agrestis L. was offered $L$. corniculatus plants of varying cyanogenic strengths.

Crawford-Sidebotham's (1972) results on the effect of alternative food also suggest that choice experiments of the type carried out here should be more sensitive for detecting discrimination by herbivores than are differential eating trials. This means, however, that these experiments may overestimate the selection differential in relation to what occurs in wild populations where other plant species would be present. It is noticeable that a higher proportion of cyanogenic clover was eaten in the field survey (Angseesing and Angseesing, 1973).

In the $A$. ater experiment several hundred leaflets, cyanogenic and acyanogenic, were severed from their petioles without being eaten. As the aim of the experiments was to determine whether cyanogenicity was advantageous to the plant in the presence of herbivores these leaflets were scored as destroyed by the herbivores even though they had not been consumed. This may give a good estimate of the proportion of cyanogenic 
eaflets which are destroyed under the experimental conditions pertaining but it underestimates the ability of the herbivores to discriminate.

If a herbivore avoids eating cyanogenic plants then one may conclude that it has evolved a sensory system for detecting HCN and a behavioural mechanism causing it to reject cyanogenic food. It is also likely that the herbivore rejects a cyanogenic diet because it is advantageous to do so (Bishop and Korn, 1969). It is possible, however, that the concentration of HCN in $\mathcal{T}$. repens is not harmful to slugs but is still sufficient to activate the behavioural mechanism of rejection. Ingesting cyanide may be disadvantageous without being lethal and none of the experimenters working on selectivity have reported mortality differences between animals fed on cyanogenic and those fed on acyanogenic plants. The cyanide, a respiratory poison, may merely slow an animal's metabolism sufficiently to reduce its reproductive potential. Whereas the effects of cyanogenic plants on mammals have been documented (e.g. Montgomery, 1969), little work has been reported on these effects on other animal species. To support their conclusion of non-selectivity in $H$. aspersa Bishop and Korn (1969) reported that there was no difference in growth rate between snails fed on cyanogenic and those fed on acyanogenic clover. In view of Crawford-Sidebotham's (1972) differential results for selection by this species it could be that growth, like mortality, is not a suitable short-term criterion for detecting an effect caused by cyanogenic plants. Some recent work (M. Wilkinson, unpublished) has detected a significant decline in the oxygen uptake of $A$. ater individuals fed solely on cyanogenic clover as compared with controls fed on acyanogenic clover.

The question as to how herbivores distinguish cyanogenic and acyanogenic plants is still unresolved. Even prolonged exposure of picrate papers near undamaged leaves fails to detect any HCN released (Jones, 1966). One possibility is that the habit of severing leaflets and whole leaves from their petioles without eating either may release $\mathrm{HCN}$ in small amounts and give the slugs warning. There are, however, at least two other possible explanations for this behaviour: it may be a captivity syndrome or it may be a means of reducing the bulk of the food. In the latter case a species would possess a behavioural pre-adaptation which could readily evolve into a means of detecting cyanogenic leaves. The large proportion of cyanogenic leaves which are found to be nibbled by slugs (Angseesing and Angseesing, 1973) may be evidence that the animals are unable to distinguish cyanogenic leaves until they have damaged them and released some HCN. Bishop and Korn (1969) suggested that cyanogenic plants would obtain no selective advantage if herbivores nibbled their leaves because this would cause HCN release and plant tissue death due to self-poisoning. Cyanogenic leaves, however, appear to be well able to survive and even continue to develop after they have been damaged; it is not uncommon to find mature cyanogenic leaves bearing bilaterally symmetrical nibbled edges, suggesting that the leaf was grazed before it had opened out.

It would be interesting to know whether the molluscs of Scandinavia and Central Europe, where the proportion of cyanogenic clover is low (Daday, 1954), are as selective in their feeding as those of Great Britain. If a plant evolves a protective measure such as toxicity then its herbivores may evolve a detoxifying mechanism or a behavioural means such as selective feeding to evade the toxicity. The whole question of co-evolution between 
cyanogenic plants and their grazers and parasites has recently been reviewed by Jones $(1973 b)$. It is quite possible for the herbivore to maintain a cyanide resistant/non-resistant polymorphism or a behavioural polymorphism correlating with the distribution of the cyanogenesis polymorphism in its food. Also of possible future interest are the populations of $L$. corniculatus and T. repens established by man (Jones, 1973a, b) which often have very different cyanogenic plant frequencies from their neighbours. Cyanide tolerance has been obtained in a relatively short time by artificial selection in Drosophila melanogaster Meigen (Harrison, 1952) so it is possible that local variations in the physiology or habits of herbivores could be correlated with these local discontinuities in the cyanogenesis polymorphism.

Acknowledgments. - I thank Dr T. J. Crawford-Sidebotham for performing many of the significance tests and for discussions, W. J. Angseesing and Dr D. A. Jones for discussions and D. Russell for his assistance in phenotyping the clover plants.

\section{RefERENCES}

ANGseesing, J. P. A., And Angseesing, w. J. 1973. Field observations on the cyanogenesis polymorphism in Trifolium repens L. Heredity, 31, 276-282.

BISHOP, J. A., AND KORN, M. E. 1969. Natural selection and cyanogenesis in white clover, Trifolium repens. Heredity, 24, 423-430.

CORKILL, L. 1952. Cyanogenesis in white clover (Trifolium repens L.). VI. Experiments with high-glucoside and glucoside-free strains. N.Z. J. Sci. Tech., 34, A, 1-16.

CRAWFORD-SIDEBOTHAM, T. J. 1972. The role of slugs and snails in the maintenance of the cyanogenesis polymorphisms of Lotus corniculatus and Trifolium repens. Heredity, 28, $405-411$.

DADAY, H. 1954. Gene frequencies of wild populations of Trifolium repens L. I. Distribution by latitude. Heredity, 8, 61-78.

DADAX, H. 1955. Cyanogenesis in strains of white clover (Trifolium repens L.). J. Brit. Grassland Soc., 10, 266-274.

DADAY, H. 1965. Gene frequencies in wild populations of Trifolium repens L. IV. Mechanism of natural selection. Heredity, 20, 355-365.

FOULDS, W., AND GRIME, J. P. 1972. The response of cyanogenic and acyanogenic phenotypes of Trifolium repens to soil moisture supply. Heredity, 28, 181-187.

harrison, B. J. 1952. Tolerance to hydrogen cyanide. A. Rept. John Innes Hort. Inst., 43, 16.

JONEs, D. A. 1962. Selective eating of the acyanogenic form of the plant Lotus corniculatus L. by various animals. Nature, 193, 1109-1110.

JONEs, D. A. 1966. On the polymorphism of cyanogenesis in Lotus corniculatus L.I. Selection by animals. Can. 7. Genet. Cytol., 8, 556-567.

JONEs, D. A. 1970 . On the polymorphism of cyanogenesis in Lotus corniculatus L. III. Some aspects of selection. Heredity, 25, 633-641.

JONEs, D. A. 1973a. On the polymorphism of cyanogenesis in Lotus corniculatus L. V. Denmark. Heredity, in press.

Jones, D. A. 1973b. Coevolution and cyanogenesis. Proc. Symp. Syst. Assn., in press.

MONTGOMERY, R. D. 1969. Cyanogens. In Toxic Constituents of Plant Foodstuff, Ed. I. E. Liener, 143-157. Academic Press.

SNEDECOR, G. W., AND COCHRAN, w. G. 1971. Statistical Methods, 6th ed. Iowa State University Press, Ames, Iowa. 